\section{ZEW}

Zentrum für Europäische Wirtschaftsforschung GmbH

Centre for European Economic Research

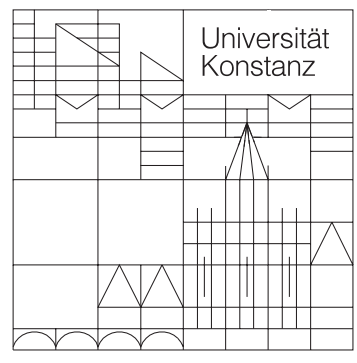

Rechts-, Wirtschafts- und Verwaltungswissenschaftliche Sektion

Fachbereich

Wirtschaftswissenschaften

Diskussionspapiere der DFG-

Forschergruppe (Nr.: 3468269275):

Heterogene Arbeit: Positive und Normative Aspekte der Qualifikationsstruktur der Arbeit

Oliver Fabel

Firm Foundations and Human Capital Investments: The 0-Ring Approach to Organizational Equilibrium in an Emerging Industry

Mai 2003 


\title{
Firm Foundations and Human Capital Investments: The 0-Ring Approach to Organizational Equilibrium in an Emerging Industry Oliver Fabel
}

\author{
Universität Konstanz \\ Fach D 144 \\ 78457 Konstanz \\ Germany \\ mail : oliver.fabel@uni-konstanz.de \\ phone : +49-7531-88-2992 \\ fax : $+49-7531-88-4456$
}

\begin{abstract}
:
The current analysis introduces human capital investments which - as all other investment projects - must be carried out given ex-ante uncertain returns. This return uncertainty reflects that particular ex-post ability realizations may or may not induce the possibility to engage in profitable entrepreneurial activity. Managed firms which recruit randomly while offering a certain wage-income cannot be kept from entering the industry. However, if it is individual beneficial to seek employment in such firms, given that human capital investments are sunk, the resulting industry structure provides less incentives to invest than a purely entrepreneurial industry. While it remains true that entrepreneurial firms - if they exist - are founded by teams of superior realized abilities, the equilibrium analysis reveals a rather different perspective of the incentive mechanism. Human capital investments are not so much necessary in order to induce entrepreneurial activity. Rather, entrepreneurial activity provides the effective incentives to invest in human capital. This distinction is important to note. Due to the risk-shifting property associated with employment in managed firms, policies directed at maximizing entrepreneurial activities will generally fail to implement an efficient solution. As with every other incentive mechanism, incentive compatibility constitutes a constraint on the possibility to achieve a first-best solution.
\end{abstract}

\author{
JEL Classification : D21, D31, D82, J41 \\ Keywords : Firm Foundations; O-Ring Theorie; Human Capital Investments; Market Selection; \\ Risk-Shifting
}

Download/Reference : http://www.ub.uni-konstanz.de/kops/volltexte/2003/999/ 


\title{
Firm Foundations and Human Capital Investments:
}

\author{
The O-Ring Approach to Organizational Equilibrium \\ in an Emerging Industry
}

\section{Prof. Dr. Oliver Fabel}

Faculty of Law, Economics, Public Policy \& Management, Department of Economics, University of Konstanz, 78457 Konstanz, Germany; Voice: +49-7531-88-2990/-2992; Fax: +49-7531-88-4456; E-Mail: oliver.fabel@unikonstanz.de

\section{Introduction}

Definitions of the "New Economy" frequently refer to particular industries - such as the bio-technology, computer, and ICT industries - in which technological innovations spark off the foundation of new firms. However, there also exists an organizational economics perspective concerning the structural similarities of such New Economy firms. This view emphasizes two common features. First, within these industries production appears to be characterized by positive externalities between specialized tasks. Second, employees are exposed to incentive schemes which induce ownership-like income claims. Thus, in corporate firms employees are typically motivated by offering stock or stock option plans.

Concerning the first characteristic feature noted above, (Rajan and Zingales 2000, 2001a) remark that the innovations themselves originate from human capital rather than inanimate firm assets. The individual member of the production team possesses necessary skills and knowledge. This argument not only implies a fundamental shift of power towards human capital. The production process is further characterized by a super-modular technology, respectively positive complementarities among team members assigned to specialized tasks. It can be shown that flat hierarchies dominate in the organization of such processes ${ }^{1}$. Moreover, following (Prat

\footnotetext{
${ }^{1}$ (Rajan and Zingales 2001b).
} 
2002) the optimal recruitment policy aims at composing homogeneous production teams.

Given flat hierarchies, "up-or-out"-options set incentives to specialize for young professionals ${ }^{2}$. New Economy start-ups therefore reflect that the outside opportunity has become dominant over the specialist's career. The business idea is then typically based on innovations encountered during the founder's previous employment ${ }^{3}$. It follows that positive complementarities also apply to the production in these new firms. Hence, "unusual judgement and perceptiveness" in employee selection constitutes a prime success factor in New Economy firms ${ }^{4}$. However, in contrast to wellestablished firms, the start-ups are not restrained by "corporate culture" rules of equal treatment when selecting their personnels.

Turning to the characteristic second feature, ownership-like management incentive schemes constitute the single most important characteristic of New Economy firms ${ }^{6}$. (Holderness et al. 2001) report that management shareholdings have increased significantly over the 1980-90s. Such schemes serve as self-selection devices when attracting employees ${ }^{7}$. However, the professionals in such firms are then also exposed to project risk. The poor performance of the stock or stock option plans vis-à-vis soaring financial markets thus induces the necessity of further compensation ${ }^{8}$ and motivation problems ${ }^{9}$. These arguments imply that risk-aversion of the New Economy partic ipants limits the scope of the newly founded firms.

(Fabel 2002) has shown that these two characteristic properties - positive complementarities in production and risk-aversion on the side of firm founders - can induce a separating industry equilibrium. The partic ular ORing production technology ${ }^{10}$, which is introduced in detail below, allows to link individual abilities directly to project risk. Given this separating equilibrium, high-ability individuals found entrepreneurial firms as partnerships of ability-matched teams. In this respect, (Bhidé 2000, p. 94) re-

${ }^{2}$ (Rajan and Zingales 2001b).

3 (Bhidé 2000, p. 54).

${ }^{4}$ (Bhidé 2000, p. 54).

5 (Bhidé 2000, p. 324).

${ }^{6}$ (Audretsch and Thurik 2001).

7 (Bhidé 2000, p. 87, 200).

${ }^{8}$ (Zingheim and Schuster 2000).

${ }^{9}$ (Weinberg 2001).

${ }^{10}$ The term "O-Ring production" refers to the Challenger accident which is blamed on the malfunctioning of a simple earring. As an analogy, the productivity of the team is taken to depend entirely on the weakest team member's productivity. 
Firm Foundations and Human Capital Investments:

ports that New Economy firm founders are in fact characterized by superior educational backgrounds.

However, the existence of such an equilibrium requires that the ability spread within the group of industry professionals must be sufficiently large. The benefits of self-selecting by founding a new firm must more than compensate the risk-premium. Clearly, the realized ability spread depends on ex-ante individual human capital investments. At the same time, the incentives to invest in human capital just as obviously depend on the industry's ex-post organizational structure. More precisely, the strength of these incentives reflect the degree of entrepreneurial activity in the industry. Only existing options to found new firms can yield a benefit of selfselection.

Hence, the current analysis introduces human capital investments which - as all other investment projects - must be carried out given ex-ante uncertain returns. The return risk reflects that particular ex-post ability realizations may or may not induce the possibility to engage in profitable entrepreneurial activity. Managed firms which recruit randomly while offering a certain wage-income cannot be kept from entering the industry. However, if it is individually beneficial to seek employment in such firms, given that human capital investments are sunk, the resulting industry structure provides less incentives to invest than a purely entrepreneurial industry.

While it remains true that entrepreneurial firms - if they exist - are founded by teams of realized superior abilities, the equilibrium analysis reveals a rather different perspective of the incentive mechanism. Human capital investments are not so much necessary in order to induce entrepreneurial activity. Rather, entrepreneurial activity provides the effective incentives to invest in human capital. This distinction is important to note. Due to the risk-shifting associated with employment in managed firms, policies directed at maximizing entrepreneurial activities will generally fail to implement an efficient solution. As with every other incentive mechanism, incentive compatibility constitutes a constraint on the possibility to achieve a first-best solution.

The remainder of the paper is organized as follows. The next section introduces the basic assumptions and notations. Section 3 then investigates the incentives to invest in human capital, given that the industry consists of managed, respectively entrepreneurial firms only. The following section 4 investigates the ex-ante investment ncentives which endogenously arise given the induced ex-post industry equilibrium. Since all propositions de- 
rived in section 4 are interpreted in detail, the final section 5 then only provides a brief concluding discussion.

\section{Basic assumptions}

Suppose that $K, K \geq 2$, separate tasks must be performed simultaneously in order to produce output. The output good becomes more sophisticated and, thus, more valuable for consumers as the number of tasks defined in the production process increases. Per-capita revenue is therefore given by $r(K)$, with $r(K)>0$, for $K>0$, and $r^{\prime}(K)>0$. Yet, in contrast to (Fabel 2002), the number of tasks is exogenous throughout the current analysis. It reflects the state of the art in production in a newly emerging industry. Thus, for notational simplicity $r(k) \equiv \bar{r}$ in the following.

Further, following (Kremer 1993), positive output can only be realized if all $K$ production tasks are performed perfectly. If a single member of the production team fails in performing the task assigned to her, the output of the whole group is destroyed. This so-called O-Ring theory of production implies that team production is characterized by positive complementarities $^{11}$.

Assuming that each task is carried out by exactly one team member, let $q_{i}$ then denote the probability of perfect task performance of team member $i, \bar{i}=1, \ldots, K$. Given the assumption above, total revenue thus equals

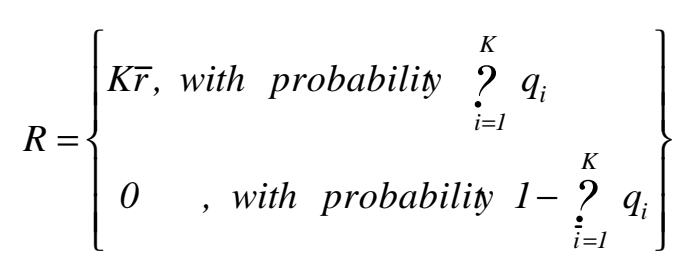

Team members stem from a population of ex-ante identical individuals. Before being recruited and assigned to production tasks, each individual can invest in human capital. The respective investment level is denoted $a_{j}, j=1, \ldots, N$, where $N$ refers to population size. It will be assumed that $0 \leq a_{j} \leq 1$. Individual quality if assigned to a productive task then constitutes a random variable which is distributed uniformly over the interval

\footnotetext{
${ }^{11}$ Positive complementarities constitute a special case of the more general concept of super-modular technologies. Compare (Prat 2002).
} 
Firm Foundations and Human Capital Investments:

The O-Ring Approach to Organizational Equilibrium in an Emerging Industry 5

$\left[0, a_{j}\right]$ for individual $j$. Since $E\left\{q \mid a_{j}\right\}=\frac{a_{j}}{2}$, investments in human capital therefore enhance the productive quality of the individual.

The human capital investments must be made before production commences. Individual preferences are characterized by an identical instantaneous utility function $u=\ln \left(y-c a_{j}\right)$, where $y \geq 0$ denotes income and $c>$ 0 the investment costs. Assuming logarithmic utility - thus, constant relative risk aversion - serves to simplify the analysis. All individuals then also possess exogenous income $\bar{y}>0$.

Suppose that all individuals are assigned to productive tasks in $N / K$ firms. Further, there exists an investment equilibrium implying $a_{j}^{*}=\tilde{a}, \forall j=1, \ldots, N$. Then, if firms select workers randomly, the expected firm revenue can be obtained as

$$
E R^{\text {random }}=\prod_{i=1}^{K} E\left\{q \mid a_{i}=\tilde{a}\right\} K \bar{r}=\left(\frac{\tilde{a}}{2}\right)^{K} K \bar{r}
$$

On the other hand, if individuals of identical qualities can be matched within firms, the average expected revenue over all such firms equals

$$
E R^{\text {matched }}=\int_{0}^{\tilde{a}} q^{K} 1 / \tilde{a} d q \bar{r} K=\frac{\tilde{a}^{K}}{(K+1)} \bar{r} K
$$

Due to $K \geq 2, E R^{\text {matched }}>E R^{\text {random }}$. Hence, taking the ex-ante perspective, all individuals who have not yet realized this productive quality would strictly prefer to enter an economy in which production teams are quality-matched. Moreover,

$$
\frac{\partial E R^{\text {matched }}}{\partial \tilde{a}}=\bar{r} \frac{K^{2}}{(K+1)} \tilde{a}^{(K-1)}>0
$$

and

$$
\frac{\partial^{2} E R^{\text {matched }}}{[\partial \tilde{a}]^{2}}=\bar{r} \frac{K^{2}(K-1)}{(K+1)} \tilde{a}^{(K-2)}>0
$$

for $K \geq 2$. Thus, the productive advantages of matching teams of identical quality imply economy-wide increasing returns to human capital investments. 
Note that production will be weakly preferred over no production, if $\ln \left(\bar{y}+\frac{\bar{r} \tilde{a}^{K}}{(K+1)}-c \tilde{a}\right) \geq \ln (\bar{y})$. Inserting $\tilde{a}=1$ then reveals that

$$
\frac{\bar{r}}{(K+1)} \geq c
$$

is sufficient to induce the first-best investment level $\tilde{a}=1$, due to the increasing returns implied by (4) and (5).

However, implementing the first-best solution requires a transfer scheme which provides a certain income equal to the average expected per-capita revenue for all individuals. The project risk would have to be distributed over the whole population. Yet, in this case all individuals would obviously prefer $a_{j}=0, \forall j=1, \ldots, N$.

Hence, the income opportunities of a competitive economy must provide sufficient incentives to induce human capital investments. In the following, it is therefore assumed that individuals may found partnerships. Since every partner is a member of the production team herself, she can also verify each ther team member's productive quality. Furthermore, partnerships can enforce individual attachments or separations respectively. Thus, partnerships can form matched production teams.

At the same time, they can only distribute realized revenue among their partners. Due to the quality risk associated with each team member, partnership income is thus always subject to project risk. Partnerships will therefore be denoted entrepreneurial firms in the following. Clearly, if there exist such firms in industry equilibrium, the first-best will not be implemented. Partnerships preclude risk-sharing.

Since the production technology is common knowledge, the already existing Old Economy may also integrate part of the industry. Within these firms managers are responsible for employee selection. Since the managers do not participate in the production process themselves, they cannot verify individual qualities. Alternatively, it can be assumed that the corporate culture of these firms precludes the necessary wage-differentiation. Such managed firms therefore hire randomly from the pool of potential employees in the industry. However, they will also pay a certain salary $w^{m}$. Thus, employees of managed firms do not face income risk, but their firms are subject to quality risk.

Then, assuming that there exists an equilibrium such that $a_{j}^{*}=\tilde{a}, \forall j=1, \ldots, N$, with the superscript “*” referring to individually 
Firm Foundations and Human Capital Investments:

The O-Ring Approach to Organizational Equilibrium

optimal investment levels, three possible types of organizational equilibria can be distinguished:

- the pure equilibrium in which there exist only entrepreneurial firms;

- $\quad$ the pure equilibrium in which there exist only managed firms;

- $\quad$ mixed equilibria in which entrepreneurial and managed firms coexist.

\section{Firm types and human capital investments}

Clearly, all firms are subject to the project risk associated with their employees', respectively their partners' failure in task performance. Realizing zero profit therefore does not signal a lack of productive quality. Moreover, if managed firms conditioned their salary on project success, individuals would always prefer to join a partnership. This follows from the fact that managed firms cannot observe individual qualities and, thus, do not implement quality-matched teams.

Hence, the only way to successfully compete with partnerships is to offer risk-free salaries when contracting with employees. The expected profit of a managed firm can be derived as

$$
E ?=\prod_{i=1}^{K} \underset{a^{m}}{E}\left\{\underset{q}{E}\left\{q \mid a^{m}\right\}\right\} \bar{r} K-w^{m} K
$$

with $a^{m} \equiv\left\{a_{i}^{m}\right\}$ denoting the ability profile. The expectation operator $\underset{a^{m}}{E}\{\ldots\}$ serves as a reminder that managed firms cannot observe neither quality realizations nor human capital investment levels.

The firm's expectation concerning the ability profile of its employees must be entirely based on anticipating the equilibrium human capital investments. It is assumed that the non-cooperative Nash-equilibrium concept applies. Recalling that all individuals are ex-ante identical, the equilibrium investments in human capital satisfy $a_{j}^{*}=\tilde{a}, \forall j=1, \ldots, N$. Hence, $a_{j}^{*}$ denotes the individually optimal choice, given that all other members of the population, $k \neq j$, choose $a_{k}=\tilde{a}$.

It then follows:

Proposition 1: The new industry cannot emerge as an equilibrium consisting of managed firms only. 
Proof: Suppose an equilibrium with $a_{j}^{*}=\tilde{a}, \forall j=1, \ldots, N$, exists and the new industry consists of managed firms only. Given the firms' antic ipation of the equilibrium human capital investment level, (7) implies

$$
\begin{aligned}
E \tilde{\Pi} & =E\left\{q_{i} \mid \tilde{a}\right\} \bar{r} K-w^{m} K \\
& =\left(\frac{\tilde{a}}{2}\right)^{K} \bar{r} K-w^{m} K
\end{aligned}
$$

Again, managed firms cannot observe the quality realizations of their employees.

Clearly, offering a fixed income $w^{m}$ when recruiting employees, managed firms cannot avoid to incur losses of size $-w^{m} K$, with probability $(\tilde{a} / 2)^{K}$. Competition among these firms implies zero expected profits. Thus, the salary level equals

$$
w^{m}(\tilde{a})=\left(\frac{\tilde{a}}{2}\right) \bar{r}
$$

Note once more that this salary level only depends on the equilibrium investment level $\tilde{a}$. However, each employee actually possesses a fixed income claim. Thus, the individuals choose their investment level $a_{j}, j=1, \ldots, N$, such as to maximize $\ln \left(\bar{y}+w^{m}-c a_{j}\right)$. Clearly, $a_{j}^{*}=0$. Hence, with managed firms only, $\tilde{a}=0$ also constitutes the only possible equilibrium human capital investment level. In this case $w^{m}(\tilde{a} \mid \tilde{a}=0)=0$ and production in the new industry does not take place.

Q.E.D.

Obviously, individual incomes must internalize at least part of the project risk in order to provide incentives for human capital investments. Given the distinction of only two firm types above, this requires the existence of some entrepreneurial firms in the industry. Thus, let $\bar{q}^{p}=\left\{q_{1}^{p}, q_{2}^{p}, \ldots, q_{K}^{p}\right\}$ denote the ability profile of partnership $p, p=1, \ldots$, $P$. The expected utility from participating in this partnership can then be derived as

$$
E u_{j}^{p}=\prod_{i=1}^{K} q_{i}^{p} \ln \left(\bar{y}+\bar{r}-c a_{j}\right)+\left(1-\prod_{i=1}^{K} q_{i}^{p}\right) \ln \left(\bar{y}-c a_{j}\right)
$$

for each partner $j, j=1, \ldots, K$. Without loss of generality, (10) assumes that total revenue $\bar{r} K$ is distributed equally across partners.

Then, note that 


$$
\begin{aligned}
\frac{\partial E u_{j}^{p}}{\partial q_{j}^{p}} & =\prod_{k \neq j}^{K} q_{k}^{p}\left[\ln \left(\bar{y}+\bar{r}-c a_{j}\right)-\ln \left(\bar{y}-c a_{j}\right)\right] \\
& \equiv \prod_{k \neq j}^{K} q_{k}^{p} \Delta\left(K, a_{j}\right)>0
\end{aligned}
$$

for each partner $j \neq k$. Moreover,

$$
\frac{\partial\left[\partial E u_{j}^{p} / \partial q_{j}^{p}\right]}{\partial\left[\prod_{k \neq j}^{K} q_{k}^{p}\right]}=\Delta\left(K, a_{j}\right)>0
$$

Thus, joining partnerships which already consist of relatively high quality team members will always be more attractive than entering partnerships characterized by a relatively poor quality profile $\bar{q}^{p}=\left\{q_{i}^{p}\right\}$. At the same time, existing partnerships will compete for the highest quality team member available in the industry's pool of potential partners. These arguments imply that, in equilibrium, all partnerships consist of team members of identical quality. Hence, $q_{i}^{p}=q^{p}, \forall i=1, \ldots, K$. Entrepreneurial firms $p$, $p=1, \ldots, P$, differ with respect to team quality, while exhibiting a homogeneous ability profile.

Given that entrepreneurial firms always exploit the benefits of abilitymatching, let $\tilde{a} \geq 0$ again denote an equilibrium human capital investment level. Consider an organizational equilibrium in the industry consisting of entrepreneurial firms only. The size of the population is taken to be sufficiently large. Thus, the individual probability to realize quality $q_{i} \in[q, q+\delta q], i=1, \ldots, N$, translates into the relative frequency of respective quality-matched partnerships among the total of $N / K$ entrepreneurial firms. Furthermore, divisibility problems associated with allocating individuals characterized by quality realizations $q \in[0, \tilde{a}]$ to matched groups of $K$ partners are ignored.

Then, if individual $j$ chooses the human capital investment level $a_{j} \leq \tilde{a}$ and subsequently realizes quality $q \in\left\lfloor 0, a_{j}\right\rfloor$, she will be able to join a partnership of team quality $q$ with probability one. If she decides on $a_{j}>\tilde{a}$, the probability to find and join a partnership of team quality $q \in[0, \tilde{a}]$ is again one. However, she may also realize quality $q \in\left(\tilde{a}, a_{j}\right\rfloor$, in which case she cannot team up with partners of identical quality. Then recall (11)- 
(12). The expected utility of all $(K-1)$ partners increases when a superior-ability partner is attracted. Hence, all existing partnerships will accept individual $j$. She can therefore freely choose which firm to join. Obviously, she will join a partnership which offers the highest expected utility of all.

Hence, given her believe $a_{k}=\tilde{a}, k=1, \ldots, N$ and $j \neq k$, individual $j$ 's ex-ante expected utility can be obtained as:

$$
\begin{aligned}
& W\left(a_{j}, \tilde{a}\right)= \\
& \Phi \int_{0}^{a_{i}}\left[\ln \left(\bar{y}+\bar{r}-c a_{j}\right) q^{K}+\ln \left(\bar{y}-c a_{j}\right)\left(1-q^{K}\right)\right] y_{a_{j}} d q \\
& \quad+(1-\Phi)\left\{\int_{0}^{\tilde{a}}\left[\ln \left(\bar{y}+\bar{r}-c a_{j}\right) q^{K}+\ln \left(\bar{y}-c a_{j}\right)\left(1-q^{K}\right)\right] y_{a_{j}} d q\right. \\
& \left.\quad+\int_{\widetilde{a}}^{a_{j}}\left[\ln \left(\bar{y}+\bar{r}-c a_{j}\right)(\tilde{a})^{(K-l)} q+\ln \left(\bar{y}-c a_{j}\right)\left(1-(a)^{(K-l)} q\right)\right] y_{a_{j}} d q\right\} \\
& \quad=\ln \left(\bar{y}-c a_{j}\right)+\Delta\left(K, a_{j}\right)\left\{\Phi \frac{\left(a_{j}\right)^{K}}{(K+1)}+(1-\Phi)\left[\frac{(\tilde{a})^{(K+l)}}{(K+1) a_{j}}+\frac{1}{2}(\tilde{a})^{(K-l)}\left(a_{j}-\frac{(\tilde{a})^{2}}{a_{j}}\right)\right]\right\}
\end{aligned}
$$

with

$$
\Phi=\left\{\begin{array}{l}
0, \text { for } a_{j}>\tilde{a} \\
1, \text { for } a_{j} \leq \tilde{a}
\end{array}\right.
$$

Since all entrepreneurial firms implement perfect quality-matching, a single individual's choice of human capital investment affects the probability to be able to join a team of a particular quality. Hence, participating in an entrepreneurial firm provides incentives to invest in human capital. If individual $j$ should choose $a_{j}=0$, the probability of earning $\bar{r}$ by joining an entrepreneurial firm equals zero with certainty.

The following can then be shown:

Proposition 2: Suppose the newly emerging industry consists only of entrepreneurial firms. Then, there exist two locally stable equilibria. One equilibrium is characterized by $a_{j}=\tilde{a}=0, \forall j=1, \ldots, N$. However, for $\bar{y}>c$ and sufficiently large returns to productive activity $\bar{r}$, there also exists an equilibrium in which all individuals choose the efficient investment level $a_{j}=\tilde{a}=1$.

Proof:

For $\Phi=1$, 


$$
\begin{aligned}
\left.\frac{\partial W\left(a_{j}, \tilde{a}\right)}{\partial a_{j}}\right|_{\Phi=l} & =\frac{-c}{\bar{y}-c a_{j}}+\left[\frac{c}{\bar{y}-c a_{j}}-\frac{c}{\bar{y}+\bar{r}-c a_{j}}\right] \frac{\left(a_{j}\right)^{K}}{(K+1)} \\
& +\Delta\left(K, a_{j}\right) \frac{K}{(K+1)}\left(a_{j}\right)^{(K-l)} \\
\left.\frac{\partial^{2} W\left(a_{j}, \tilde{a}\right)}{\left|\partial a_{j}\right|^{2}}\right|_{\Phi=1} & =\frac{c^{2}}{\left(\bar{y}-c a_{j}\right)^{2}}+\left[\frac{c^{2}}{\left(\bar{y}+\bar{r}-c a_{j}\right)^{2}}-\frac{c^{2}}{\left(\bar{y}-c a_{j}\right)^{2}}\right] \frac{\left(a_{j}\right)^{K}}{(K+1)} \\
& +2\left[\frac{-c}{\bar{y}+\bar{r}-c a_{j}}+\frac{c}{\bar{y}-c a_{j}}\right] \frac{K}{(K+1)}\left(a_{j}\right)^{(K-1)} \\
& +\Delta\left(K, a_{j}\right) \frac{K(K-1)}{(K+1)}\left(a_{j}\right)^{(K-2)}
\end{aligned}
$$

Also, for $\Phi=0$,

$$
\begin{aligned}
& \left.\frac{\partial W\left(a_{j}, \tilde{a}\right)}{\partial a_{j}}\right|_{\Phi=0}=\frac{-c}{\bar{y}-c a_{j}} \\
& +\left[\left(\frac{1}{K+1}-1 / 2\right) \frac{(\tilde{a})^{(K+l)}}{a_{j}}+1 / 2(\tilde{a})^{(K-l)} a_{j}\right]\left[\frac{c}{\bar{y}-c a_{j}}-\frac{c}{\bar{y}+\bar{r}-c a_{j}}\right] \\
& +\left[-\left(\frac{1}{K+1}-1 / 2\right) \frac{(\tilde{a})^{(K+1)}}{\left(a_{j}\right)^{2}}+1 / 2(\tilde{a})^{(K-I)}\right] \Delta\left(K, a_{j}\right) \\
& \left.\frac{\partial^{2} W\left(a_{j}, \tilde{a}\right)}{\left.\partial \partial a_{j}\right]^{2}}\right|_{\Phi=0}=\frac{c^{2}}{\bar{y}-c a_{j}} \\
& +\left[\left(\frac{1}{K+1}-1 / 2\right) \frac{(\tilde{a})^{(K+l)}}{a_{j}}+1 / 2(\tilde{a})^{(K-1)} a_{j}\right]\left[\frac{c^{2}}{\bar{y}+\bar{r}-c a_{j}}-\frac{c}{\bar{y}-c a_{j}}\right] \\
& +2\left[-\left(\frac{1}{K+1}-1 / 2\right) \frac{(\tilde{a})^{(K+1)}}{\left(a_{j}\right)^{2}}+1 / 2(\tilde{a})^{(K-l)}\right]\left[\frac{c}{\bar{y}-c a_{j}}-\frac{c}{\bar{y}+\bar{r}-c a_{j}}\right] \\
& +\left[2\left(\frac{1}{K+1}-1 / 2\right) \frac{(\tilde{a})^{(K+1)}}{\left(a_{j}\right)^{3}}\right] \Delta\left(K, a_{j}\right)
\end{aligned}
$$

Note that (15) is monotonically increasing in $a_{j}$. Thus assume that all individuals $k, k=1, \ldots, N$ with $k \neq j$ choose $a_{j}=\tilde{a}=1$. Moreover, individual $j$ correctly anticipates these investment choices. Then, the case characterized by $\Phi=1$ must apply. Inserting $a_{j}=1$ into (15) reveals: 


$$
\begin{aligned}
& \left.\frac{\partial W\left(a_{j} l\right)}{\partial a_{j}}\right|_{\Phi=1}>0 \\
& \Leftrightarrow c\left[\frac{1}{\bar{y}-c}+\frac{1}{K} \frac{1}{\bar{y}+\bar{r}-c}\right]<\Delta\left(K, a_{j}\right) \\
& \Leftrightarrow c \leq \frac{\bar{r}}{1 / K+\frac{\bar{y}+\bar{r}-c}{\bar{y}-c}}
\end{aligned}
$$

by virtue of Jensen's inequality. Hence, $a_{j}^{*}=1$ is optimal for individual $j$, if the final condition in (19) is satisfied (sufficient condition). Since this applies to every individual, given that she anticipates that all others choose this investment level, $\tilde{a}=1$ constitutes a Nash-equilibrium. Noting that, for $\bar{y}>c$, the RHS of (19) is monotonically increasing in $\bar{r}$ yields the qualif ication reported in the proposition.

The second possible Nash-equilibrium is more easily identified. If $a_{k}=\tilde{a}=0$, for all $k=1, \ldots N$ with $k \neq j$, only the case characterized by $\Phi=0$ can apply. Obviously, individual $j$ 's optimal choice then satisfies $a_{j}^{*}=0$ as well. Finally, both second derivations (16) and (18) are clearly strictly positive. Hence, an interior optimum $a_{j}^{*} \in(0,1)$ for some $a_{k}=\tilde{a} \in(0,1)$, with $k \neq j$, cannot exist.

Q.E.D.

If individual $j$ believes that all others will not invest in human capital, she anticipates that all projects will be unsuccessful with certainty. Hence, she will not invest herself either. In contrast, if she believes that everyone else chooses the efficient investment level, this choice will also constitute her individual optimum.

However, two conditions must then further be satisfied. First, she must be able to finance her own education. Second, the activity must be sufficiently productive such that per-capita revenue compensates for the cost of education and the risk-premium. Hence, while such an organizational equilibrium provides sufficient incentives to induce the efficient human capital investment level, it clearly does not implement the first-best. 
Firm Foundations and Human Capital Investments:

The O-Ring Approach to Organizational Equilibrium

in an Emerging Industry

\section{Endogenous organizational equilibrium and human capital investments}

Effective incentives for human capital investments can only stem from entrepreneurial activity. However, propositions 1 and 2 assume the existence of either one of the two possible pure organizational equilibria. As for mixed industry equilibria in which both firm types coexist, the following holds:

Proposition 3: Suppose the equilibrium human capital investments satisfy $a_{j}=\tilde{a}>0, \quad \forall j=1, \ldots, N$. Then, an organizational equilibrium consisting of both managed and entrepreneurial firms is characterized by a separating quality level $\tilde{q}$, with $0<\tilde{q}<1$. Individuals realizing qualities $q>\tilde{q}$ team up to found ability-matched partnerships. In contrast, all individuals realizing qualities $q \leq \widetilde{q}$ seek employment in managed firms which randomly recruit from the labor pool characterized by $q \in[0, \tilde{q}]$.

Proof: Suppose that within the interval of possible quality realizations $[0, \tilde{a}]$ there exist four non-trivial subintervals $Q_{1}=\left[q_{0}, \widetilde{q}_{1}\right)$, $Q_{2}=\left[\tilde{q}_{1}, \tilde{q}_{2}\right), Q_{3}=\left[\tilde{q}_{2}, \tilde{q}_{3}\right)$, and $Q_{4}=\left[\tilde{q}_{3}, \tilde{q}_{4}\right]$, with $0 \leq q_{0}<\tilde{q}_{4} \leq \tilde{a}$, such that individuals realizing qualities $q \in Q_{2}$ and $q \in Q_{4}$ voluntarily seek employment in managed firms, while individuals of qualities $q \in Q_{1}$ and $q \in Q_{3}$ prefer to found partnerships.

The expected utility $E U^{P}(q)$ derived from participating in abilitymatched partnerships monotonically increases with team quality $q$ :

$$
\frac{\partial E U^{P}(q)}{\partial q}=K q^{(K-1)} \Delta\left(K, a_{j}\right)>0
$$

Thus, individuals characterized by $q \in\left[0, \tilde{q}_{1}\right)$ will also prefer employment in a managed firm over founding partnerships. Since quality cannot be observed in managed firms, these individuals cannot be prevented from entering such firms. Hence, $\widetilde{q}_{1}=0$ and $Q_{1}$ constitutes an empty set.

Let $w^{m}\left(Q_{2} Q_{4}\right)$ denote the certain wage-income offered by such managed firms. They can randomly recruit among individuals characterized by $q \in Q_{2}$ and $q \in Q_{4}$. By construction, the following would be implied:

$$
E U^{p}(q)<\ln \left(\bar{y}+w^{m}\left(Q_{2} Q_{4}\right)-c\right), \forall q \in Q_{2}
$$




$$
\begin{aligned}
& E U^{p}(q)>\ln \left(\bar{y}+w^{m}\left(Q_{2} Q_{4}\right)-c\right), \forall q \in Q_{3} \\
& E U^{p}(q)<\ln \left(\bar{y}+w^{m}\left(Q_{2} Q_{4}\right)-c\right), \forall q \in Q_{4}
\end{aligned}
$$

Again, according to (20), the expected partnership utility monotonically increases in team quality $q$. Hence, the inequalities (21) cannot hold simultaneously. The proposition thus follows by contradiction.

Q.E.D.

If some ability-matched groups ever found partnerships, all individuals characterized by higher qualities will also prefer this option over joining a managed firm. Every mixed organizational equilibrium which can prevail in the new industry is therefore characterized by a single quality level $\tilde{q}$ which separates managed firm employment from entrepreneurial activity.

Given this characterization, the Nash-equilibrium consequences for human capital investments must be addressed. As in Propositions 1 and 2, the behavioral effects can be obtained by maximizing the respective expected utility:

$$
\begin{aligned}
& W\left(a_{j}, \tilde{a}\right)=\Phi\left\{\Psi\left[\ln \left(\bar{y}+\left(\frac{\tilde{q}}{2}\right)^{K} \bar{r}-c a_{j}\right)\right]\right. \\
& +(1-\Psi)\left[\int_{0}^{\tilde{q}} \ln \left(\bar{y}+\left(\frac{\tilde{q}}{2}\right)^{K} \bar{r}-c a_{j}\right) d q 1 / a_{j}\right. \\
& \left.\left.\quad+\int_{\tilde{q}}^{a_{j}}\left[\ln \left(\bar{y}+\bar{r}-c a_{j}\right) q^{K}+\ln \left(\bar{y}-c a_{j}\right)\left(1-q^{K}\right)\right] d q 1 / a_{j}\right]\right\} \\
& +(1-\Phi)\left\{\Psi\left[\ln \left(\bar{y}+\left(\frac{\tilde{q}}{2}\right)^{K} \bar{r}-c a_{j}\right)\right]\right. \\
& \quad+(1-\Psi)\left[\int_{0}^{\tilde{q}} \ln \left(\bar{y}+\left(\frac{\tilde{q}}{2}\right)^{K} \bar{r}-c a_{j}\right) d q 1 / a_{j}\right. \\
& \quad+\int_{\tilde{q}}^{\tilde{a}}\left[\ln \left(\bar{y}+\bar{r}-c a_{j}\right) q^{K}+\ln \left(\bar{y}-c a_{j}\right)\left(1-q^{K}\right)\right] d q 1 / a_{j} \\
& \left.\left.\quad+\int_{\tilde{a}}^{a_{j}}\left[\ln \left(\bar{y}+\bar{r}-c a_{j}\right)(\tilde{a})^{K-1)} q+\ln \left(\bar{y}-c a_{j}\right)\left(1-\tilde{a}^{(K-1)} q\right)\right] d q 1 / a_{j}\right]\right\}
\end{aligned}
$$

with 
Firm Foundations and Human Capital Investments:

$$
\begin{aligned}
& \Phi= \begin{cases}1, \text { if } a_{j} \leq \tilde{a} \\
0, \text { if } a_{j}>\tilde{a}\end{cases} \\
& \Psi= \begin{cases}1, \text { if } a_{j} \leq \tilde{q} \\
0, \text { if } a_{j}>\tilde{q}\end{cases}
\end{aligned}
$$

and $(\tilde{q}, \tilde{a})$ defined above. Note that, if $a_{j} \leq \tilde{q},-$ hence $\Psi=1-$ individual $j$ will join a managed firm with certainty. Only if $a_{j}>\tilde{q}$, the option of teaming up with partners of identical quality $q>\widetilde{q}$ to found an entrepreneurial firm arises. Then, if the individual's optimal choice entails $a_{j}^{*} \leq \tilde{q}$, symmetry implies that $\tilde{a}=0$ must constitute the unique Nashequilibrium. Thus, whether or not this case applies hinges on the incentives to found partnerships. Since these incentives depend on equilibrium investment level $\tilde{a}$ again, it is useful to note the following:

Proposition 4: Suppose the industry structure constitutes a mixed equilibrium. Hence, $\widetilde{q}$, with $0<\widetilde{q}<1$, separates intervals of realized qualities such that individuals characterized by $q \leq \tilde{q}(q>\tilde{q})$ prefer to be employed by managed firms (to found entrepreneurial firms). Then, the $e x$ ante equilibrium human capital investment level must satisfy $\tilde{a}=1$.

Proof: The first-order condition for interior optimal with respect to $a_{j}$ can be derived as

$$
\begin{aligned}
& \frac{\partial}{\partial a_{j}}\left[\left.W\left(a_{j}, \tilde{a}\right)\right|_{\Phi=1} ^{\Psi=1}\right] \stackrel{!}{=} 0=-\frac{c}{\bar{y}-c a_{j}}-\tilde{\Delta}\left(K, a_{j}\right)\left[\frac{\tilde{q}}{\left(a_{j}\right)^{2}}\right] \\
& +\Delta\left(K, a_{j}\right)\left[K a_{j}^{(K-1)}+\frac{\tilde{q}^{(K+1)}}{\left(a_{j}\right)^{2}}\right](K+1) \\
& +\left[\frac{\tilde{q}}{a_{j}}\right]\left[\frac{c}{\bar{y}-c a_{j}}-\frac{c}{\bar{y}+\bar{r}\left(\frac{\tilde{q}}{2}\right)^{K}-c a_{j}}\right] \\
& +\left[a_{j}{ }^{K}-\frac{\tilde{q}^{(K+1)}}{a_{j}}\right]\left[\frac{c}{\bar{y}-c a_{j}}-\frac{c}{\bar{y}+\bar{r}-c a_{j}}\right], \\
& \text { respectively }
\end{aligned}
$$




$$
\begin{aligned}
& \frac{\partial}{\partial a_{j}}\left[\left.W\left(a_{j}, \tilde{a}\right)\right|_{\Phi=0} ^{\Psi=1}\right] \stackrel{!}{=} 0=-\frac{c}{\bar{y}-c a_{j}}-\tilde{\Delta}\left(K, a_{j}\right)\left[\frac{\tilde{q}}{\left(a_{j}\right)^{2}}\right] \\
& +\Delta\left(K, a_{j}\right)\left[-\frac{\tilde{a}^{(K+1)}}{(K+1)\left(a_{j}\right)^{2}}+\frac{\tilde{q}^{(K+1)}}{(K+1)\left(a_{j}\right)^{2}}+1 / 2+1 / 2\left(\frac{\tilde{a}}{a_{j}}\right)^{2}\right. \\
& +\left[\frac{\tilde{q}}{a_{j}}\right]\left[\frac{c}{\bar{y}-c a_{j}}-\frac{c}{\bar{y}+\bar{r}(\tilde{q} / 2)^{K}-c a_{j}}\right] \\
& +\left[\frac{\tilde{a}^{(K+1)}}{(K+1) a_{j}}-\frac{\tilde{q}^{(K+1)}}{(K+1) a_{j}}+1 / 2 a_{j}-1 / 2\left(\frac{\tilde{a}^{2}}{a_{j}}\right)\right]\left[\frac{c}{\bar{y}-c a_{j}}-\frac{c}{\bar{y}+\bar{r}-c_{j}}\right]
\end{aligned}
$$

with $\tilde{\Delta}\left(K, a_{j}\right) \equiv\left[\ln \left(\bar{y}+\bar{r}\left(\frac{\tilde{q}}{2}\right)^{K}-c a_{j}\right)-\ln \left(\bar{y}-c a_{j}\right)\right]$ and $\Delta\left(K, a_{j}\right)$ defined above. Obviously, (24) and (25) again distinguish the consequences of choosing $a_{j}^{*} \leq \tilde{a}$, respectively $a_{j}^{*}>\tilde{a}$, for $j=1, \ldots, N$. If $\tilde{a} \in(0,1)$ constitutes a Nash-equilibrium human capital investment level, both conditions must hold for $a_{j}=\tilde{a}$. Insertion in (24) and (25) can then be seen to yield

$$
\begin{gathered}
\frac{\partial}{\partial a_{j}}\left[\left.W\left(a_{j}, \tilde{a} \mid a_{j}=\tilde{a}\right)\right|_{\Phi=0} ^{\Psi=1}\right]-\frac{\partial}{\partial a_{j}}\left[\left.W\left(a_{j}, \tilde{a} \mid a_{j}=\tilde{a}\right)\right|_{\Phi=1} ^{\Psi=1}\right]= \\
\Delta(K, \tilde{a})\left[1-\tilde{a}^{(K-1)}\left(\frac{1}{K+1}+\frac{K}{K+1}\right)\right]= \\
\Delta(K, \tilde{a})\left(1-\tilde{a}^{(K-1)}\right)>0
\end{gathered}
$$

Clearly, (26) not only contradicts that $\tilde{a}$, with $0<\tilde{q}<\tilde{a}<1$, may constitute a Nash-equilibrium. Since (25) reflects the change in expected utility as the individual increases her investment level $a_{j}$, the positive sign in (26) also implies that $a_{j}=\tilde{a}=1$ constitutes the only possible equilibrium choice in this case.

Q.E.D.

If both firm types coexist in equilibrium, the individuals will always enter managed firms with positive probability. In this case they cannot benefit from the productive advantage of ability-matched teams. Hence, deriving the second-order conditions associated with (24) and (25) respectively, 
Firm Foundations and Human Capital Investments:

The O-Ring Approach to Organizational Equilibrium in an Emerging Industry

the possibility of an interior individual optimum $a_{j}{ }^{*} \in(0,1)$, for $\tilde{a} \in(0,1)$ cannot be excluded a priori.

However, (22) highlights a second, unambiguously positive effect of increasing the individual investment level $a_{j}$ above the level $\tilde{a}$ which she believes to be chosen by all others. She can increase the probability of joining a partnership characterized by the highest realized quality level in the industry.

While this effect also occurs in (15) and (17), it is not necessary to prove Proposition 2. In contrast, it turns out to be decisive in generating the positive sign in (26). The possibility to join an entrepreneurial firm with a top-ability team more than compensates for the reduction in investment incentives due to the coexistence of managed firms.

Proposition 4 then allows to compute the equilibrium expected utility, given a particular industry structure. It follows:

Proposition 5: (a) If $\bar{r}(1 / 2)^{K} \geq c$, there always exists an organizational equilibrium with efficient human capital investments $\tilde{a}=1$. Hence, the new industry will emerge as long as individual $j, j=1, \ldots N$, ex-ante believes $a_{k}=\tilde{a}=1, k \neq j$.

(b) Given $a_{j}=\tilde{a}=1, j=1, \ldots, N$, it further follows:

(i) If $(1 / 2)^{-K}-1 \geq \frac{\bar{r}}{\bar{y}-c}$, there can only exist a pure organizational equilibrium such that the industry consists entirely of entrepreneurial firms.

(ii) If $(1 / 2)^{-K}-1 \leq \frac{\bar{r}}{\bar{y}-c}$, there exists at least one, but possibly more than one mixed equilibrium.

Proof: Consider the difference between the expected utility derived from a marginal partnership combining $K$ individuals of identical ability $\widetilde{q}$ and the certain utility associated with joining a managed firm which randomly recruits among individuals characte rized by $q \in[0, \widetilde{q})$. Assuming $\tilde{q} \geq 0$,

$$
E U^{P}(\tilde{q})-\ln \left(\bar{y}+w^{m}(\tilde{q})-c\right)=
$$




$$
\begin{array}{r}
\ln (\bar{y}+\bar{r}-c) \tilde{q}^{K}+\ln (\bar{y}-c)\left(1-\tilde{q}^{K}\right) \\
-\ln \left(\bar{y}+\bar{r}\left(\frac{\tilde{q}}{2}\right)^{K}-c\right) \geq \\
\quad \tilde{r}^{K}\left[\frac{1}{\bar{y}+\bar{r}-c}-\frac{(1 / 2)^{K}}{\bar{y}-c}\right]
\end{array}
$$

by virtue of Jensen's Inequality. Note that (27) has been derived setting $a_{j}=\tilde{a}=1, j=1, \ldots, N$, as implied by Proposition 4. Moreover, for $\bar{r}>0$, (27) holds with strict inequality. Part (b)-(i) of Proposition 5 then provides the condition under which this expression is positive for all possible values of $\tilde{q}>0$. If it satisfied, only entrepreneurial firms can exist in the industry.

However, even given that all individuals have chosen $a_{j}=\tilde{a}=1$, the reverse merely constitutes a necessary condition for the existence of a mixed equilibrium. Moreover, $E U^{P}(0)=\ln (\bar{y}-c)=\ln \left(\bar{y}+w^{m}(0)-c\right)$. Hence, in order to show whether there actually exists an incentive to join a managed firm upon investing $a_{j}=\tilde{a}=1$, the difference in first derivatives must be accounted for:

$$
\begin{gathered}
\frac{\partial E U^{P}(\tilde{q})}{\partial \tilde{q}}-\frac{\partial \ln \left(\bar{y}-w^{m}(\tilde{q})-c\right)}{\partial \tilde{q}}= \\
K \widetilde{q}^{(K-1)} \Delta\left(K, a_{j}\right)- \\
K \tilde{q}^{(K-1)}(1 / 2)^{K} \frac{\bar{r}}{\bar{y}+\bar{r}\left(\frac{\tilde{q}}{2}\right)-c} \leq \\
\bar{r} \tilde{q}^{(K-1)}\left[\frac{1}{\bar{y}+\bar{r}-c}-\frac{(1 / 2)^{K}}{\bar{y}+\bar{r}(\tilde{q} / 2)-c}\right]
\end{gathered}
$$

Again, (28) uses Jensen's Inequality and strict equality follows from $\bar{r} \geq 0$. The term in quantities obviously becomes negative for $\lim (\widetilde{q}) \rightarrow 0$, if the condition noted in part (b)-(ii) of Proposition 5 is satisfied. Hence, for infinitesimal, but positive values of $\tilde{q}$, the certain utility associated with managed firm employment increases at higher rates than the expected utility derived from joining the marginal entrepreneurial firm. Hence, there must exist $\tilde{q} \in[0, \delta)$, with $\delta>0$, such that employment in a 
Firm Foundations and Human Capital Investments:

The O-Ring Approach to Organizational Equilibrium in an Emerging Industry

managed firm constitutes the preferred choice for individuals realizing qualities $q<\tilde{q}$ upon having invested $\tilde{a}=1$.

Part (a) of Proposition 5 is more easily proved then. If $\bar{r}\left(\frac{1}{2}\right)^{K} \geq c$, investing $a_{j}=\tilde{a}=1$ yields an equilibrium in which the ex-ante expected utility is weakly higher compared to the situation with no production in the new industry. In the latter case, everyone consumes $\bar{y}>0$. The ex-ante expected utility is even strictly higher, if there exist some entrepreneurial firms. While (6) above therefore remains necessary for the emergence of the new industry, the inequality reported in part (a) of Proposition 5 constitutes a sufficient condition.

If it is satisfied there exists an equilibrium with at least some entrepreneurial firms. Above, this equilibrium has been shown to be locally stable with respect to the ex-ante individually optimal choices of human capital investments. Also, it globally dominates the solution $\tilde{a}=0$ which necessarily emerges, if there exist only managed firms in the industry.

Q.E.D.

Conditions (i) and (ii) in Proposition 5(b) reflect the strength of the incentives to found entrepreneurial firms in industry equilibrium. Thus, $\bar{r} /(\bar{y}-c)$ measures the benefit-loss ratio associated with organizing the firm as a partnership. If this ratio is reduced, the adverse effect of project risk on expected partnership utility ceteris paribus decreases.

On the other hand, for large ratios $\bar{r} /(\bar{y}-c)$, risk-averse individuals will always prefer to possess the ption of receiving a certain utility in managed firms. Their risk-premium associated with being exposed to project risk as members of entrepreneurial firms exceeds the expected income loss which - due to random recruiting - has to be incurred when joining a managed firm.

The strength of this incentive to found partnerships as well as the possibility to realize an equilibrium outcome with efficient human capital investments both depend on the size of the per-capita revenue $\bar{r}$. Thus, very large $\bar{r}$-values induce two effects which on first sight appear contradictory.

First, the emergence of the new industry becomes more likely and, given that production then actually becomes profitable, an equilibrium with managed firms only cannot exist. Second, ceteris paribus relatively large per-capita revenue associated with successful production also induce a tendency towards profitable market-entrance of managed firms. 
Hence, while entrepreneurial firms are necessary to provide human capital investment incentives, highly productive new industries will also be particularly attractive for managed firms. Their market entrance reduces the incentives to invest in human capitalagain. The mere presence of managed firms thus decreases the likelihood that the new industry will actually emerge.

Comparing condition (6) with part (a) of Proposition 5, the emergence of the new industry requires per-capita revenue $\bar{r} \in\left(\frac{K+1}{K} c,(1 / 2)^{-K} c\right)$. Hence, focussing exclusively on the potential productive benefits of a new industry - in particular, assuming a first-best solution could be implemented - generally underestimates the actual chances to experience the emergence of such an industry.

Furthermore, part (a) of Proposition 5 additionally requires that all individuals actually believe that everyone else will invest efficiently in human capital. As shown in Proposition 2, there always exists a stable equilibrium characterized by investments $a_{j}=\tilde{a}=0, \forall j=1, \ldots, N$, as well. If regulating and subsidizing formal education would implement a lower bound for realized productive qualities, this outcome could generally be avoided.

Hence, an educational policy which ensures that every individual in the economy is characterized by a strictly positive probability of perfect task performance will enhance the likelihood of new industry emergence. Yet, given the incentives for managed firms' market entrance, ensuring minimum educational standards alone cannot guarantee the emergence of a new industry.

Since this result holds even if commencing production in this new industry is efficient, additional governmental aid such as tax-benefits, or subsidized venture capital for entrepreneurial firms can be welfareenhancing. However, as shown below, the success of such subsidies can not be measured in terms of maximizing entrepreneurial activity.

Case (ii) of Proposition 5(b) still offers the possibility of multiple mixed equilibria. In this respect, the following can be shown:

Proposition 6: Consider Proposition 5.

(a) Given part (b)-(ii) of the proposition, multiple mixed equilibr ia will generally exist. Let $\tilde{q}_{s}$ denote the respective separating quality level of the mixed equilibrium $s, s=1, \ldots, S$. Then, there always exists a unique efficient equilibrium characterized by $\widetilde{q}^{*}=\max \left\{\tilde{q}_{s}\right\}$. 
Firm Foundations and Human Capital Investments:

The O-Ring Approach to Organizational Equilibrium in an Emerging Industry 21

(b) If the initial wealth net of human capital investment costs approaches zero, the equilibrium industry structure tends to consist of entrepreneurial firms only.

Proof: Increasing $\tilde{q}$ implies

$$
\frac{\partial \ln \left(\bar{y}+w^{m}(\tilde{q})-c\right)}{\partial \tilde{q}}=\frac{(1 / 2) \bar{r}(\tilde{q} / 2)^{(K-1)} K}{\left(\bar{y}+w^{m}(\tilde{q})-c\right)}>0
$$

and

$$
\begin{aligned}
\frac{\partial^{2} \ln \left(\bar{y}+w^{m}(\tilde{q})-c\right)}{[\partial \tilde{q}]^{2}}= & \frac{1 / 4 K(K-1) \bar{r}(\tilde{q} / 2)^{K-2)}(\bar{y}-c)}{\left(\bar{y}+w^{m}(\tilde{q})-c\right)^{2}} \\
& +\frac{(1 / 4)(\bar{r})^{2}(\tilde{q} / 2)^{2 K}\left[\frac{(K-1)}{K}-1\right]}{\left(\bar{y}+w^{m}(\tilde{q})-c\right)^{2}} \stackrel{>}{=} 0
\end{aligned}
$$

Similarly, the expected utility associated with participating in a marginal partnership of team quality $q$ changes according to

$$
\frac{\partial E U^{P}(q)}{\partial q}=K q^{(K-1)} \Delta(K, 1)>0
$$

in equilibrium with efficient human capital investments. Also,

$$
\frac{\partial^{2} E U^{P}(q)}{(\partial q)^{2}}=(K-1) K q^{(K-2)} \Delta(K, 1)>0
$$

since $K \geq 2$.

In mixed equilibrium $\ln \left(\bar{y}+w^{m}(\widetilde{q})-c\right)=E U^{P}(\widetilde{q})$. However, given the ambiguous sign of (30), a single-crossing property of $\ln \left(\bar{y}+w^{m}(q)-c\right)$ and $E U^{P}(q)$ cannot be established. Hence, in general there will be mult iple intersection of the two functions.

Each of these intersections - characterized by a separating ability level $\tilde{q}_{s}, s=1, \ldots, S$-constitutes a mixed equilibrium. Since both the expected utility derived from participating in a partnership and the certain utility associated with managed firm employment are monotonically increasing in $q$, the equilibrium characterized by $\tilde{q}^{*}=\max \left\{\tilde{q}_{s}\right\}$ then dominates. These arguments imply part (a) of Proposition 6. 
Finally, note that

$$
\lim _{(\bar{y}-c) \rightarrow 0}\left[\frac{\partial^{2} \ln \left(w^{m}(\tilde{q})+\bar{y}-c\right)}{[\partial q]^{2}}\right]=\frac{1 / 4(\bar{r})^{2}\left(\frac{\tilde{q}}{2}\right)^{2 K}\left(\frac{(K-1)}{K}-1\right)}{\left(w^{m}(\tilde{q})\right)^{2}}<0
$$

Hence, (32) and (33) imply the existence of a unique mixed equilibrium as initial wealth net of human capital investment costs approaches zero. It further follows:

$$
\begin{aligned}
\frac{\frac{\partial E U^{P}(\tilde{q})}{\partial q}}{\frac{\partial \ln \left(\bar{y}+w^{m}(\tilde{q})-c\right)}{\partial q}}= & \frac{\Delta(K, 1)\left(\bar{y}+w^{m}(\tilde{q})-c\right)}{(1 / 2)^{K} \bar{r}} \\
& \geq \frac{\bar{r} \frac{\left(\bar{y}+w^{m}(\tilde{q})-c\right)}{(\bar{y}+\bar{r}-c)}}{(1 / 2)^{K} \bar{r}}
\end{aligned}
$$

given Jensen's Inequality again. Thus,

$$
\lim _{(\bar{y}-c) \rightarrow 0}\left\{\frac{\frac{\partial E U^{P}(\tilde{q})}{\partial q}}{\frac{\partial \ln \left(\bar{y}+w^{m}(\tilde{q})-c\right)}{\partial q}}\right\} \geq \frac{(1 / 2)^{K}}{(1 / 2)^{K}}=1
$$

with strict inequality since $\bar{r}>0$. Recall that $E U^{P}(0)=\ln (\bar{y}-c)$ and $\ln \left(\bar{y}+w^{m}(0)-c\right)=\ln (\bar{y}-c)$. Thus, if there exists an equilibrium with positive production and investments, it must be a pure equilibrium with entrepreneurial firms only. This argument is summarized in part (b) of Proposition 6.

Q.E.D.

Part (a) of Proposition 6 demonstrates the danger of misperception of the equilibrium mechanism by policy-makers. On the one hand, without entrepreneurial activity there exist no incentives to invest in human capital. On the other hand, maximizing the entrepreneurial activity in an industry does not yield an efficient solution.

In general, there will exist multiple mixed organizational equilibria. The equilibrium characterized by the highest separating ability level dominates. 
Firm Foundations and Human Capital Investments:

The O-Ring Approach to Organizational Equilibrium

in an Emerging Industry 23

However, compared to all other possible equilibria, entrepreneurial activity is minimized by choosing this equilibrium.

By paying a certain income independent of project risk, managed firms provide an insurance against poor ex-post realization of abilities. At the same time, their mere existence reduces the incentives to invest in human capital. This typical adverse incentive effect of income insurance cannot be avoided. Once the individuals have invested in human capital, managed firms cannot be kept from entering the industry.

This dilemma is also highlighted in part (b) of Proposition 6. Suppose policy-makers would actually wish to maximize entrepreneurial activity. The proposition suggests that this can be achieved by increasing the individual cost of human capital investments. Thus, a policy of cutting the personal subsidies for educational programs may appear suitable.

However, the desired entrepreneurial activities will clearly only result, if it remains individually beneficial to invest in human capital at all. Increasing the private investment costs clearly also yields an incentive to withhold such investments though. Thus, the attempt to maximize entrepreneurial activity is likely to achieve the non-emergence of the new industry.

\section{Concluding discussion}

Given the rather complex theoretical model, it appears worthwhile to discuss the restrictive nature of some of the assumptions introduced. Thus, assuming that the number of tasks in production is exogenously fixed for the industry and across firms is certainly subject to doubts. However, (Kremer 1993) already shows that team sizes can be determined endogenously. Higher team ability then implies an increasing team size.

(Fabel 2002) then considers team size and capital investments as continuously variable inputs given a standard Cobb-Douglas per-capita revenue function. Separating in dustry equilibria will still emerge under rather general conditions. In particular, the paper is based on general instantaneous utility functions.

However, his previous paper assumes an exogenous distribution of abilities in the population. Hence, the current model adds the analysis of ex-ante risky individual human capital investments. In this respect, the assumption that such investments constitute a neutral "bad" exhibiting constant unit investment costs possesses great simplifying virtue. Combining this assumption with the particular O-Ring revenue function, realized investments can only be either efficient or equal to zero. 
Alternatively, marginal investment costs could be taken to increase. In this case, both first-best and second-best investment evels may constitute interior solutions of the individual optimization problem. Yet, only the discussion of Proposition 6 appears to require qualific ation. Comparing different possible equilibria, varying degrees of entrepreneurial activity will then also induce different levels of human capital investments. Hence, stimula ting entrepreneurial activity may actually possess a welfare enhancing quality per se.

However, the main result of the above analysis appears robust and warrants to be reemphasized. Obviously, it is true that the emergence of a new industry is driven by the entrepreneurial activities of high-ability professional teams. Still, this observation does not lend support for programs directed at improving the entrepreneurial abilities of potential firm founders. Rather, investigating the equilibrium mechanism, it is more important to realize that such entrepreneurial activity is necessary in order to provide effective incentives for human capital investments.

As with every other incentive mechanism, the art of policy-making must then be concerned with achieving a balance between simultaneously setting adequate investment incentives and allowing for sufficient riskshifting through employment in managed firms. Generally, it is questionable whether public policy can actually "walk this narrow bridge" - for instance, by founding public venture capital funds or providing consulting services at no costs. Corporate venturing by established managed firms offering the possibility of voluntary spin-offs for high-profile employees should be considered the dominant mechanism.

\section{References}

Audretsch DB, Thurik AR (2001) What's New About the New Economy? Sources of Growth in the Managed and the Entrepreneurial Economies. Industrial and Corporate Change 10:267-315

Bhidé AV (2000) The Origin and Evolution of New Businesses. Oxford University Press, New York

Fabel, O (2002) Spin-Offs of Entrepreneurial Firms: The O-Ring Approach. Discussion Paper Series I - 314, rev. version (first version entitled: The Emergence of a New economy: An O-Ring Approach), Department of Economics, University of Konstanz

Holderness CG, Krosner RS, Sheehan DP (1999) Were the Good Old Days That Good? Changes in the Managerial Stock Ownership Since the Great Depression. Journal of Finance 54:435-470

Kremer M (1993) The O-Ring Theory of Economic Development. Quarterly Journal of Economics 108: 551-575. 
Firm Foundations and Human Capital Investments:

The O-Ring Approach to Organizational Equilibrium in an Emerging Industry 25

Prat A (2002) Should a Team Be Homogeneous? European Economic Review 46:1187-1207

Rajan RG, Zingales L (2000) The Governance of the New Enterprise. In: Vives X (ed.) Corporate Governance: Theoretical and Empirical Rerspective. Cambridge University Press, Cambridge, pp. 201-227

Rajan RG, Zingales L (2001a) The Influence of the Financial Revolution on the Nature of Firms. American Economic Review 91: 206-211

Rajan RG, Zingales L (2001b) The Firm as a Dedicated Hierarchy: A Theory of the Origin and Growth of Firms. Quarterly Journal of Economics 116: 805851

Weinberg CR (2001) Reward Strategies for Dot.Corp Organizations: Lessons from the Front. Compensation and Benefit Review 33: 6-14

Zingheim PK, Schuster JR (2000) Total Rewards for New and Old Economy Companies. Compensation and Benefit Review 32: 20-33. 